\title{
The Prevalence of Sensorineural Hearing Loss (SNHL) In the Elderly, Lokoja, Nigeria: A Five-Year Review.
}

\author{
Dr Stephen Agbomhekhe Ogah \\ Consultant Otolaryngologist, Head and Neck Surgeon, O.R.L Division, Department of Surgery, Federal \\ Medical Centre, P.O.Box 1256, Lokoja, Nigeria.
}

\begin{abstract}
:
Background: The process of aging is associated with degenerative changes in all parts of the human body including the neural and sensory aspect of the ear. Hearing loss is one of the disabling diseases found common in elderly patients due to these degenerative changes.

Objective: To determine the prevalence and common causes of sensorineural hearing loss in the elderly.

Materials and Method: All patients aged 65 years and above with sensorineural (SNHL) hearing loss diagnosed by Pure Tone Audiometric (PTA) test were included in the study. A total of 9,712 patients were seen and 564 (5.8\%) of them had hearing loss. From those who had hearing loss, 336(60\%) of them had diagnostic PTA test done of which $62(18.5 \%)$ were elderly that had SNHL. They include 34 males and 28 females. Their case files were retrieved from the Health Record Unit and information about their age, sex, PTA test, etiology of hearing loss were extracted, studied, analyzed, with results presented in tabular and text format.
\end{abstract}

Results: The female to male ratio was 1:1.2, prevalence of $18.5 \%$ and $67.7 \%$ of them had severe SNHL of which presbyacusis was the most common cause.

Conclusion: The prevalence of SNHL among the elderly is high and age related degenerative changes in the organ of Corti were found to be the most common cause.

Keywords: Sensorineural, Hearing loss, Elderly, Five-year, Review.

\section{Introduction}

Previous studies had shown that about 28 million U.S. adults have hearing impairment which is the third commonest disease after hypertension and arthritis; and that it affects about one-third of adults 61 to 70 years of age ${ }^{1}$. After the age of 60 years, hearing is said to be declining by about $1 \mathrm{~dB}$ per year and this was said to be worse in males than females ${ }^{2}$. In Nigeria, Aremu et $\mathrm{al}^{3}$ found in their study that $21 \%$ of the elderly patients suffer from hearing loss and this may be unnoticed in most of these patients. Even when discovered by relatives, it is often regarded as a normal process of aging and so no treatment is usually given. ${ }^{4}$

Hearing loss can be divided into three types as conductive, sensorineural and mixed. A conductive hearing loss occurs in a situation in which there is a decrease in the transmitted sound through the canal and middle ear into the inner ear. This may be caused by a problem in either the outer or middle ear. In this case there is usually no problem with the inner ear. Possible causes include wax in the ear canal, a wide perforation in the tympanic membrane, infection in the ear, fluid accumulation in the middle ear, superior canal dehiscence, tympanosclerosis, foreign body in the canal etc. This type of loss responds well to either medical or surgical treatment depending on the case. For instance, Kakehata et $\mathrm{al}^{5}$ found useful transtympanic endoscopy in the management of conductive hearing loss involving the middle ear. In sensorineural hearing loss the problem is in the inner ear or along the nerve pathway between the inner ear and the brain. This type of hearing loss may be caused by age related degenerative changes in the organ of Corti (presbyacusis), infections such as labyrithitis, noise exposure and trauma ${ }^{6-8}$. Sensorineural hearing loss is usually difficult to treat and may require a hearing device or implant ${ }^{9}$. Durga et $\mathrm{al}^{10}$ reported that the use of folic acid supplements is helpful in delaying the progression of SNHL in the elderly.

\section{Materials and Method}

This is a retrospective study of patients seen between January 2009 and December 2013 at the O.R.L. Division of the Department of Surgery, Federal Medical Centre, Lokoja. All patients aged 65 years and above with sensorineural (SNHL) hearing loss diagnosed by Pure Tone Audiometric (PTA) test were included in the study. A total of 9,712 patient were seen and 564 (5.8\%) of them had hearing loss. From those who had hearing loss, $336(60 \%)$ of them had diagnostic PTA test done and $62(18.5 \%)$ of them were elderly that had SNHL. They include 34males and 28 females. Their case files were retrieved from the Health Record Unit and information about their age, sex, PTA test, etiology of hearing loss were extracted, studied, analyzed, with results presented in tabular and text format. 


\section{Results:}

Females were 34(54.8\%) and males were $28(45.3 \%)$, the female to male ratio was $1: 1.2$ as shown in table1. A prevalent rate of $18.5 \%$ was found in this study and $67.7 \%$ of them had severe sensorineural hearing loss of which presbyacusis was the most common etieology as shown in tables 2 and 3 .

Table I: Gender Distribution.

\begin{tabular}{|l|l|l|}
\hline Gender & Frequency & $\%$ \\
\hline Male & 34 & 54.8 \\
\hline Female & 28 & 45.2 \\
\hline Total & 62 & 100 \\
\hline
\end{tabular}

Table II: Categorization of hearing loss severity

\begin{tabular}{|l|l|l|l|}
\hline Severity & Decibel $(\mathrm{dB})$ & Frequency & $\%$ \\
\hline Normal & $0-25$ & 0.0 & 0.0 \\
\hline Mild & $26-40$ & 8 & 12.9 \\
\hline Moderate & $41-70$ & 7 & 11.3 \\
\hline Severe & $71-95$ & 42 & 67.7 \\
\hline Profound & $>95$ & 5 & 8.1 \\
\hline Total & & 62 & 100 \\
\hline
\end{tabular}

Table III: Etiology of hearing Loss.

\begin{tabular}{|l|c|c|}
\hline Causes & Number & $\%$ \\
\hline Presbyacusis & 18 & 29.0 \\
\hline Noise exposure & 12 & 19.4 \\
\hline Ototoxicitis & 10 & 16.1 \\
\hline Idiopathic & 8 & 13.0 \\
\hline Imflammatory & 7 & 11.3 \\
\hline Trauma & 3 & 4.8 \\
\hline Ménière's disease & 2 & 3.2 \\
\hline Neoplasm & 2 & 3.2 \\
\hline Total & 62 & 100 \\
\hline
\end{tabular}

\section{Discussion}

A prevalent rate of $18.5 \%$ was found in this study and tends to be in agreement with most studies in other parts of the world. Presbyacusis or Age-Related Hearing Impairment (ARHI) in the elderly was found to be the most common etieology in this study. This is however not surprising as presbyacusis was earlier reported by Van Eyken et $\mathrm{al}^{11}$ to be the most common cause of hearing impairment in the elderly.

Hearing impairment in the elderly is often missed in its early stages, and so it is undertreated ${ }^{12}$. Depending upon the etiology of the hearing loss, some medical and surgical procedures have been found to be of benefit. The use of hearing aid in the amplification of sound is the mainstay of treatment. Although some elderly patients may find it difficult to accept a hearing aid probably due to their inability to get used to it or due to their dissatisfaction with its overall performance.

Lasis et $\mathrm{al}^{13}$ concluded in their study at Ibadan, Nigeria that the disability prevalence associated with hearing impairment in the elderly is high. For this reason, they suggested a policy formulation for the rehabilitation of the hearing impaired elderly individuals in resource-poor settings like ours.

Laplante-Lévesque et $\mathrm{al}^{14}$ in their study reported that there are several rehabilitation methods available to the elderly with hearing impairment. However, that the choice of any particular intervention may depend on several factors, such as convenience, expected adherence and outcomes, financial costs, hearing disability, nature of intervention, other people's experiences, recommendations, support; preventive and interim solution. They concluded by saying that the best result can be obtained from a client-centered decision making approach.

\section{References}

[1] Walling AD, Dickson GM. Hearing loss in older adults. Am Fam Physician. 2012 Jun 15; 85(12):1150-6

[2]. Lee FS, Matthews LJ, Dubno JR, Mills JH. Longitudinal study of pure-tone thresholds in older persons. Ear Hear. 2005;26(1):1-11

[3] Aremu SK, Alabi BS, Segun-Busari S, Ogah SA. Audit of otological diseases amongst elderly in Nigeria. Intl. Arch.Otorhinolaryngol.2010; 14(.2):212-216

[4]. Ogah SA, Okomanyi A. Pattern of Hearing Loss as seen at the Federal Medical Centre Lokoja, Nigeria: A Five Year Retrospective Study. Asian Journal of Pharmacy, Nursing and Medical Sciences. August 2014; 2(4):87-9

[5] Kakehata SK, Futai A, Sasaki. "Endoscopic transtympanic tympanoplasty in the treatment of conductive hearing loss: early results." Otol Neurotol 2006; 27(1): 14-9

[6]. Gates GA, Cooper JC Jr, Kannel WB, Miller NJ. Hearing in the elderly: the Framinghan cohort, 1983-1985. Part 1. Basic audiometric tests results. Ear Hear. 1990;11(4):257-256

[7]. Cruickshanks KJ, Nondahl DM, Tweed TS, et al. Education, occupation, noise exposure history and the 10 -yr cumulative incidence of hearing impairment in older adults. Hear Res. 2010;264(1-2):3-9 
[8]. Chou R, Dana T, Bougatsos C, Fleming C, Beil T. Screening adults aged 50 years or older for hearing loss: a review of the evidence for the U.S. Preventive Services Task Force. Ann Intern Med. 2011;154(5):347-355

[9] Olze H, Gräbel S, Förster U. Elderly patients benefit from cochlear implantation regarding auditory rehabilitation, quality of life, tinnitus, and stress. Laryngoscope. 2012;122(1):196-203.

[10]. Durga J, Verhoef P, Anteunis LJ, Schouten E, Kok FJ. Effects of folic acid supplementation on hearing in older adults: a randomized, controlled trial. Ann Intern Med. 2007;146(1):1-9

[11]. Van Eyken E, Van Camp G, Van Laer L. The complexity of age-related hearing impairment: contributing environmental and genetic factors. Audiol Neurootol. 2007;12(6):345-358

[12]. Pacal JT, Yueh B. Hearing deficits in the older patient: “I didn't notice anything." JAMA. 2012;307(11):1185-1194

[13] Lasisi A, Gureje O, "Disability and Quality of Life among Elderly Persons with Self-Reported Hearing Impairment: Report from the Ibadan Study of Aging," International Journal of Otolaryngology and Head \& Neck Surgery. 2013; 2(2): 63-67

[14]. Laplante-Lévesque A, Hickson L, Worrall L. Factors influencing rehabilitation decisions of adults with acquired hearing impairment. Int J Audiol. 2010;49(7):497-507 